\title{
Physical properties of spray dried acerola pomace extract as affected by temperature and drying aids
}

\author{
Germano Éder Gadelha Moreira ${ }^{a}$, Mayra Garcia Maia Costa ${ }^{\mathrm{b}}$, Arthur Cláudio Rodrigues de Souza ${ }^{\mathrm{b}}$, \\ Edy Sousa de Brito ${ }^{\mathrm{b}}$, Maria de Fátima Dantas de Medeiros ${ }^{\mathrm{a}}$, Henriette M. C. de Azeredo ${ }^{\mathrm{b}, *}$ \\ a Universidade Federal do Rio Grande do Norte, Departamento de Engenharia Química - CT, Campus Universitário UFRN, Natal/RN, CEP 59078-970, Brasil \\ ${ }^{\mathrm{b}}$ Embrapa Agroindústria Tropical, R. Dra. Sara Mesquita, 2270, Fortaleza/CE, CEP 60511-110, Brasil
}

\section{A R T I C L E I N F O}

Article history:

Received 5 November 2007

Received in revised form 15 July 2008

Accepted 16 July 2008

\section{Keywords:}

Cashew tree gum

Maltodextrin

Spray drying

Barbados cherry

\begin{abstract}
A B S T R A C T
The objective of this study was to assess the impact of some processing parameters on moisture content, flowability, hygroscopicity and water solubility of spray dried acerola pomace extract using maltodextrin and cashew tree gum as drying aids. The experiment was conducted according to Response Surface Methodology, with the independent variables being: inlet temperature $\left(170-200{ }^{\circ} \mathrm{C}\right)$, drying aid/acerola ratio (2:1-5:1), and percent replacement of maltodextrin by cashew tree gum (0-100\%). Higher inlet temperatures favored the desired physical properties of the powders, decreasing their moisture contents and hygroscopicity, and increasing flowability. The drying aids decreased the powder hygroscopicity, especially cashew tree gum (CTG), which also enhanced the powder flowability. The best processing conditions to obtain a free-flowing and least hygroscopic acerola pomace extract powder by spray drying were: inlet temperature above $194{ }^{\circ} \mathrm{C}$; drying aid/acerola solid ratio, 4:1; percent replacement of maltodextrin by CTG, at least $80 \%$.
\end{abstract}

(C) 2008 Swiss Society of Food Science and Technology. Published by Elsevier Ltd. All rights reserved.

\section{Introduction}

Acerola (Malpighia emarginata D.C.), also known as the Barbados cherry or West-Indian cherry, is present in South and Central America, as well as in some southern regions of North America (Johnson, 2003). It is a red round shaped fruit, with diameter varying from 1 to $4 \mathrm{~cm}$, with a thin, easily bruised skin. Its demand has increased in the last decades, thanks to its high ascorbic acid contents, which ranges from 1000 to $4500 \mathrm{mg} / 100 \mathrm{~g}$ (Johnson, 2003; Leung \& Foster, 1996; Mezadri, Fernández-Pachón, Villaño, García-Parrilla, \& Troncoso, 2006). Brazil is currently the world's leading producer and exporter of acerola (Mezadri et al., 2006), especially as frozen puree and juice (Yamashita, Benassi, Tonzar, Moriya, \& Fernandes, 2003). Acerola processing involves crushing and pressing of the whole fruits, generating as a byproduct a strongly red pomace, which is usually discarded despite being rich in high-value compounds (particularly vitamin C and flavonoids, both with known antioxidant properties).

Spray drying is a well-established and widely used technique to turn liquid foods into powder form. However, sugar-rich materials are difficult to spray dry, because they produce highly hygroscopic powders prone to stickiness and flowing problems. The possible

\footnotetext{
* Corresponding author. Tel.: +55 118532991849.

E-mail address: ette@cnpat.embrapa.br (H.M.C.de Azeredo).
}

consequences are impaired product stability, decreased yields (because of stickiness on the drier chamber walls), and even operational problems to the spray drier (Bhandari, Datta, \& Howes, 1997). The sticky behavior is attributed to a high concentration of low molecular weight sugars and organic acids, which have low glass transition temperatures $\left(T_{g}\right)$, being rubbery and thermoplastic at the temperatures of the chamber (Bhandari \& Hartel, 2005; Dolinsky, Maletskaya, \& Snezhkin, 2000). The fast moisture removal during spray drying results in an amorphous and highly hygroscopic product (Audu, Loncin, \& Weisser, 1978; Senoussi, Dumoulin, \& Berk, 1995). On the other hand, the stickiness does not occur when higher molecular weight carbohydrates such as maltodextrins are spray dried. Instead, they facilitate drying of sugar-rich foods, since their $T_{g}$ increasing effect reduces hygroscopicity of powders. Thus, they are frequently used as drying aids (Bhandari \& Hartel, 2005; Bhandari, Senoussi, Dumoulin, \& Lebert, 1993; Bhandari et al., 1997; Silva, Sobral, \& Kieckbusch, 2006). Some studies indicated that arabic gum has higher $T_{g}$ values than those of maltodextrin having dextrose equivalent (DE) 10 or higher (Collares, Finzer, \& Kieckbusch, 2004; Righetto \& Netto, 2000), which suggests that arabic gum may be more effective than maltodextrin to reduce powder hygroscopicity. On the other hand, the high cost and availability problems associated with arabic gum (AG) have motivated researchers to look for new materials for replacing it (McNamee, O'Riordan, \& O'Sullivan, 1998). Cashew tree gum (CTG), a complex water soluble heteropolysaccharide extracted from 
Table 1

Experimental conditions of the spray drying treatments

\begin{tabular}{|c|c|c|c|c|c|c|}
\hline \multirow[t]{3}{*}{ Treatment } & \multicolumn{6}{|c|}{ Independent variables } \\
\hline & \multicolumn{2}{|l|}{ IT } & \multicolumn{2}{|l|}{ [DA] } & \multicolumn{2}{|l|}{ CTG } \\
\hline & C & UC & C & UC & C & UC \\
\hline 1 & -1 & 176 & -1 & 2.6 & -1 & 20.2 \\
\hline 2 & 1 & 194 & -1 & 2.6 & -1 & 20.2 \\
\hline 3 & -1 & 176 & 1 & 4.4 & -1 & 20.2 \\
\hline 4 & 1 & 194 & 1 & 4.4 & -1 & 20.2 \\
\hline 5 & -1 & 176 & -1 & 2.6 & 1 & 79.8 \\
\hline 6 & 1 & 194 & -1 & 2.6 & 1 & 79.8 \\
\hline 7 & -1 & 176 & 1 & 4.4 & 1 & 79.8 \\
\hline 8 & 1 & 194 & 1 & 4.4 & 1 & 79.8 \\
\hline 9 & -1.68 & 170 & 0 & 3.5 & 0 & 50.0 \\
\hline 10 & 1.68 & 200 & 0 & 3.5 & 0 & 50.0 \\
\hline 11 & 0 & 185 & -1.68 & 2.0 & 0 & 50.0 \\
\hline 12 & 0 & 185 & 1.68 & 5.0 & 0 & 50.0 \\
\hline 13 & 0 & 185 & 0 & 3.5 & -1.68 & 0.0 \\
\hline 14 & 0 & 185 & 0 & 3.5 & 1.68 & 100.0 \\
\hline 15 & 0 & 185 & 0 & 3.5 & 0 & 50.0 \\
\hline 16 & 0 & 185 & 0 & 3.5 & 0 & 50.0 \\
\hline 17 & 0 & 185 & 0 & 3.5 & 0 & 50.0 \\
\hline
\end{tabular}

$\mathrm{C}$, coded values; UC, uncoded values; IT, inlet temperature $\left({ }^{\circ} \mathrm{C}\right)$; [DA], drying aid acerola solid ratio ( $\mathrm{g}$ of drying aid per $\mathrm{g}$ of acerola solids); CTG, degree of replacement of maltodextrin by cashew tree gum (\%).

cashew tree (Anacardium occidentale), has been pointed as a very promising material, due to its structural similarity to AG (De Paula, Heatley, \& Budd, 1998; Paula, Gomes, \& Paula, 2002; Zakaria \& Rahman, 1996). The replacement of AG by CTG, previously suggested by some authors (Owusu, Oldham, Oduro, Ellis, \& Barimah, 2005; Rosenthal, 1951), could reduce costs with AG importation and favor the cashew tree business, whose only high value added product is currently the cashew nut.

The objective of this study was to evaluate the impact of some processing conditions (inlet temperature of the spray drier, degree of replacement of maltodextrin by CTG, and drying aid/acerola ratio) on physical properties (moisture content, flowability, hygroscopicity and water solubility) of spray dried acerola pomace extract.

\section{Material and methods}

The acerola pomace, provided by the company DaFruta Indústria e Comércio S.A. (Aracati, Ceara State, Brazil), was characterized in terms of moisture content (vacuum oven method), ascorbic acid contents (redox titration with 2,6-dichloroindophenol), titratable acidity (by titration to $\mathrm{pH} 8.2$ with $\mathrm{NaOH} 0.1 \mathrm{~mol} / \mathrm{L}$ ), total and reducing sugars (titration with Fehling reagents). Official methods (AOAC, 1995) were followed for all analyses.

The acerola pomace was diluted in water (pomace/water weight ratio, 5:1), and pressed in a Skay 93 hydraulic press (Skay, São José do Rio Preto, Brazil) against a stainless steel mesh cylinder (pore size, $3 \times 10^{-4} \mathrm{~m}$ ) at $5 \times 10^{6} \mathrm{~Pa}$ for $30 \mathrm{~s}$, producing the acerola pomace extract (APE). Cashew tree gum was extracted from a single cashew tree (Fortaleza, Ceara State, Brazil) and purified as described by Torquato et al. (2004).

A tissue homogenizer (AC 620/2, Ação Científica, Piracicaba, Brazil) was used to mix APE with maltodextrin (MD) and/or cashew tree gum (CTG), according to a central composite design (Table 1) with three variables: inlet temperature $\left(170-200^{\circ} \mathrm{C}\right)$, drying aid/ acerola solid ratio (2:1-5:1), and percent replacement of MD by CTG (0-100\%). The ranges of inlet temperatures and drying aid/ acerola ratios (specially the lower limits) were based on preliminary tests, since lower temperatures and/or lower drying aid/ acerola ratios led to a very sticky material. The upper limits were defined from literature data, as well as by economic reasons. The dispersion was then filtered in a stainless steel sieve ( $0.3 \mathrm{~mm}$ mesh) in order to avoid clogging of the atomizer. The spray drying was conducted in a Mini Spray Dryer Büchi B-290 (Büchi Labortechnik AG, Flawil, Switzerland) under the following operational conditions: feed rate, $0.49 \mathrm{~kg} / \mathrm{h}$; peristaltic pump rate, $1.23 \mathrm{~kg} / \mathrm{h}$; aspirator flow rate, $5.51 \times 10^{4} \mathrm{~kg} / \mathrm{h}$.

The powders obtained by the spray drying process were packaged in sealed metallized bioriented polypropylene bags at $24 \pm 2{ }^{\circ} \mathrm{C}$ before being submitted to the following analyses.

Moisture content. It was conducted by the vacuum oven method, according to AOAC (1995).

Water solubility test. The method below was described by Eastman and Moore (1984), and modified by Cano-Chauca, Stringheta, Ramos, and Cal-Vidal (2005). $1 \mathrm{~g}$ of the powder was carefully added to $100 \mathrm{~mL}$ of distilled water under agitation in a Quimis Q-221 magnetic stirrer at $385 \mathrm{~g}$ for $5 \mathrm{~min}$. The dispersion was centrifuged at $2600 \mathrm{rpm}$ for $5 \mathrm{~min}$. An aliquot $(25 \mathrm{~mL})$ of the supernatant was transferred to a previously weighted Petri dish and vacuum-dried for $5 \mathrm{~h}$ at $105^{\circ} \mathrm{C}$. The final powder weight on the dish was used for determination of the water solubility of the product ( $\mathrm{g}$ of powder per $100 \mathrm{~g}$ of water).

Hygroscopicity test. Hygroscopicity was defined as the moisture mass $(\mathrm{g})$ absorbed by $100 \mathrm{~g}$ of the powder during 7 days of storage at $25^{\circ} \mathrm{C}$ and $90 \% \mathrm{RH}$ (in a desiccator with a barium chloride saturated solution), which was a modification from the method described by Callahan et al. (1982). Hygroscopicity values thus obtained are not to be considered as absolute values, since the powders were exposed to abusive conditions (unpacked in a high relative humidity environment). Instead, the objective of the authors was to evaluate variations among treatments.

Flowability test. It was based on measuring the angle of repose formed between the side surface and the base of a cone obtained when $10 \mathrm{~g}$ of the powder is dumped from a fixed height through a funnel on a flat horizontal surface, according to the method described by Bhandari, Datta, D'Arcy, and Rintoul (1998).

The results were analyzed by using the software Minitab 15 . The models generated to represent the responses were evaluated in terms of their $F$-ratio and $R^{2}$ coefficient. The effects of the independent variables on the physical properties of the powders were studied, and conditions were established which produced a powder with minimum hygroscopicity and maximum flowability and solubility.

Table 2

Experimental responses from the spray drying treatments

\begin{tabular}{lllll}
\hline Treatment & MC & \multicolumn{1}{l}{ ANG } & HYG & WS (\%) \\
\hline 1 & $4.52 \pm 0.21$ & $52.27 \pm 2.77$ & $51.16 \pm 2.44$ & $94.02 \pm 4.76$ \\
2 & $3.70 \pm 0.17$ & $47.36 \pm 2.21$ & $43.91 \pm 2.14$ & $95.22 \pm 4.24$ \\
3 & $4.31 \pm 0.19$ & $51.34 \pm 2.96$ & $47.12 \pm 2.38$ & $92.46 \pm 4.17$ \\
4 & $3.62 \pm 0.15$ & $46.67 \pm 2.43$ & $38.73 \pm 1.82$ & $92.20 \pm 4.68$ \\
5 & $4.95 \pm 0.22$ & $48.18 \pm 2.76$ & $46.45 \pm 2.22$ & $94.72 \pm 5.05$ \\
6 & $4.22 \pm 0.20$ & $44.95 \pm 2.98$ & $41.52 \pm 2.03$ & $96.38 \pm 4.91$ \\
7 & $3.91 \pm 0.18$ & $47.73 \pm 2.74$ & $40.31 \pm 1.90$ & $92.75 \pm 4.66$ \\
8 & $3.09 \pm 0.16$ & $43.89 \pm 2.22$ & $34.72 \pm 1.93$ & $92.74 \pm 4.82$ \\
9 & $5.43 \pm 0.25$ & $50.53 \pm 3.01$ & $56.44 \pm 2.71$ & $93.42 \pm 4.67$ \\
10 & $3.96 \pm 0.20$ & $40.60 \pm 2.54$ & $40.04 \pm 1.92$ & $93.40 \pm 4.78$ \\
11 & $5.31 \pm 0.22$ & $50.19 \pm 2.87$ & $49.10 \pm 2.42$ & $96.92 \pm 4.05$ \\
12 & $3.8 \pm 0.15$ & $45.87 \pm 2.38$ & $34.97 \pm 1.79$ & $90.97 \pm 4.11$ \\
13 & $4.65 \pm 0.21$ & $48.22 \pm 2.63$ & $49.36 \pm 2.49$ & $92.03 \pm 4.63$ \\
14 & $3.48 \pm 0.21$ & $40.19 \pm 1.96$ & $38.70 \pm 2.03$ & $93.49 \pm 4.25$ \\
15 & $4.88 \pm 0.24$ & $45.07 \pm 2.56$ & $47.34 \pm 2.81$ & $92.69 \pm 4.55$ \\
16 & $4.35 \pm 0.21$ & $43.99 \pm 2.31$ & $46.76 \pm 2.42$ & $92.61 \pm 4.16$ \\
17 & $5.17 \pm 0.27$ & $46.37 \pm 2.46$ & $48.53 \pm 2.39$ & $92.32 \pm 4.37$ \\
\hline
\end{tabular}

MC, moisture content of the powder (g/100 g); ANG, angle of repose (in degrees); HYG, hygroscopicity ( $\mathrm{g}$ absorbed water/100 g powder after 7-day storage at $25^{\circ} \mathrm{C}$, $90 \% \mathrm{RH})$; WS, water solubility. 
Table 3

Regression equations (for the coded variables) and statistical parameters of the models for the physical properties of spray dried acerola pomace extracts

\begin{tabular}{|c|c|c|}
\hline Equations & $F$-ratio & $R^{2}$ \\
\hline$\overline{\mathrm{MC}}=4.83-0.41 x_{1}-0.12 x_{1}^{2}-0.37 x_{2}-0.17 x_{2}^{2}-0.14 x_{3}-0.34 x_{3}^{2}-0.01 x_{1} x_{3}-0.24 x_{2} x_{3}$ & 1.09 & 0.83 \\
\hline ANG $=45.02-2.44 x_{1}+0.55 x_{1}^{2}-0.76 x_{2}+1.43 x_{2}^{2}-1.93 x_{3}+0.07 x_{3}^{2}-0.05 x_{1} x_{2}+0.31 x_{1} x_{3}+0.01 x_{2} x_{3}$ & 1.72 & 0.89 \\
\hline HYG $=47.65-3.94 x_{1}-0.11 x_{1}^{2}-3.36 x_{2}-2.31 x_{2}^{2}-2.63 x_{3}-1.60 x_{3}^{2}-0.23 x_{1} x_{2}+0.64 x_{1} x_{3}-0.47 x_{2} x_{3}$ & 4.17 & 0.95 \\
\hline WS $=92.51+0.19 x_{1}+0.39 x_{1}^{2}-1.48 x_{2}+0.58 x_{2}^{2}+0.38 x_{3}+0.16 x_{3}^{2}-0.39 x_{1} x_{2}+0.09 x_{1} x_{3}-0.13 x_{2} x_{3}$ & 9.72 & 0.96 \\
\hline
\end{tabular}

MC, moisture content of the powder; ANG, angle of repose; HYG, hygroscopicity; WS, water solubility.

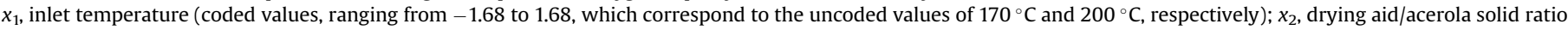

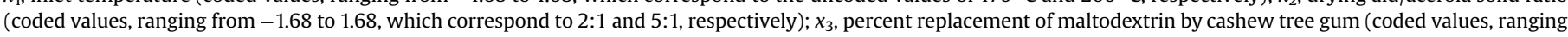
from -1.68 to 1.68 , which correspond to $0 \%$ and $100 \%$, respectively).

\section{Results and discussion}

APE presented the following basic composition: moisture content, $95.4 \mathrm{~g} / 100 \mathrm{~g}$; total and reducing sugars, $4.0 \mathrm{~g} / 100 \mathrm{~g}$ and $3.6 \mathrm{~g} / 100 \mathrm{~g}$, respectively (expressed as glucose); titratable acidity, $0.55 \mathrm{~g} / 100 \mathrm{~g}$ (expressed as malic acid). The ascorbic acid content was $0.16 \mathrm{~g} / 100 \mathrm{~g}$, corresponding to $3.56 \mathrm{~g} / 100 \mathrm{~g}$ on a dry basis. After addition of drying aids, the extracts had total solids contents in the range of $7.8-15.6 \mathrm{~g} / 100 \mathrm{~g}$.

The experimental responses of the spray drying treatments of APE are presented in Table 2, while Table 3 presents the regression coefficients for each dependent variable (response) as a function of $x_{1}$ (inlet temperature), $x_{2}$ (drying aid/acerola solid ratio), and $x_{3}$ (percent replacement of MD by CTG), as well as their statistical parameters. The moisture contents of the powders were significantly reduced by increasing all variables, mainly $x_{1}$ and $x_{2}$. The angles of repose, as well as the hygroscopicity, were also reduced by increasing all variables. For the angles of repose, the decreasing order of magnitude of their effects was $x_{1}>x_{3}>x_{2}$, and for the hygroscopicity, $x_{1}>x_{2}>x_{3}$. The water solubility was negatively affected by $x_{2}$ and favored by $x_{1}$ and $x_{3}$, mainly $x_{1}$. All the models presented $F$-ratios above 1 , indicating good description of the data by the models, and the $R^{2}$ coefficients were satisfactory. The best models were those for hygroscopicity and water solubility.

Figs. 1-4 present the contour plots for moisture content, flowability, hygroscopicity and water solubility of the powders, respectively. Increasing inlet temperature favored the physical properties of the product, since it resulted in decreased powder hygroscopicity and increased flowability (i.e., decreased angle of repose). The enhanced flowability of the powders produced at higher temperatures seems to be attributed to their lower moisture contents, since higher moisture contents impair flowability (Fitzpatrick, 2005). According to Scoville and Peleg (1981), this is due to the increase in liquid bridges and capillary forces acting between particles. The higher hygroscopicity of the powders produced at lower temperatures seems to be related to their higher moisture content. A major factor affecting powder stability is moisture content, since a small amount of water is able to depress the $T_{g}$ enough to increase the mobility of the matrix during storage (Bhandari \& Hartel, 2005; Roos, 2002; Roos \& Karel, 1992).

Increasing the drying aid/acerola ratio reduced powder hygroscopicity, confirming the behavior described in previous studies (Bhandari \& Hartel, 2005; Bhandari et al., 1993, 1997; Peleg \& Hollenbech, 1984; Silva et al., 2006). On the other hand, high proportions of the drying aid agent tended to slightly decrease the solubility of the powders, confirming results described by Abadio, Domingues, Borges, and Oliveira (2004) and Cano-Chauca et al. (2005).

Higher cashew tree gum (CTG) proportions enhanced the powder flowability and decreased hygroscopicity, suggesting that CTG is more effective than maltodextrin (MD) to increase $T_{g}$ of the powders. Although other studies about the CTG effects on $T_{g}$ have
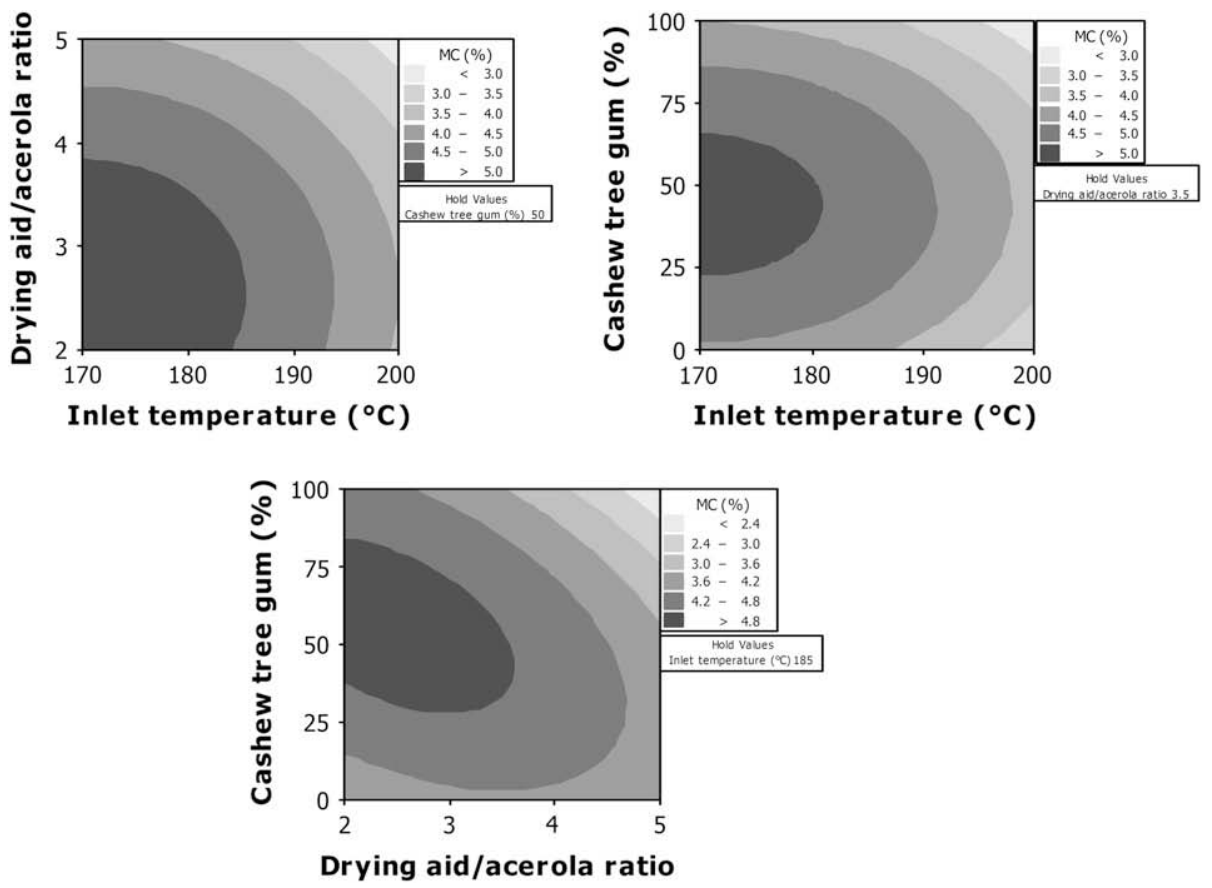

Fig. 1. Contour plots for moisture content (in $\mathrm{g} / 100 \mathrm{~g}$ ) of the powders produced by spray drying acerola pomace extract. 

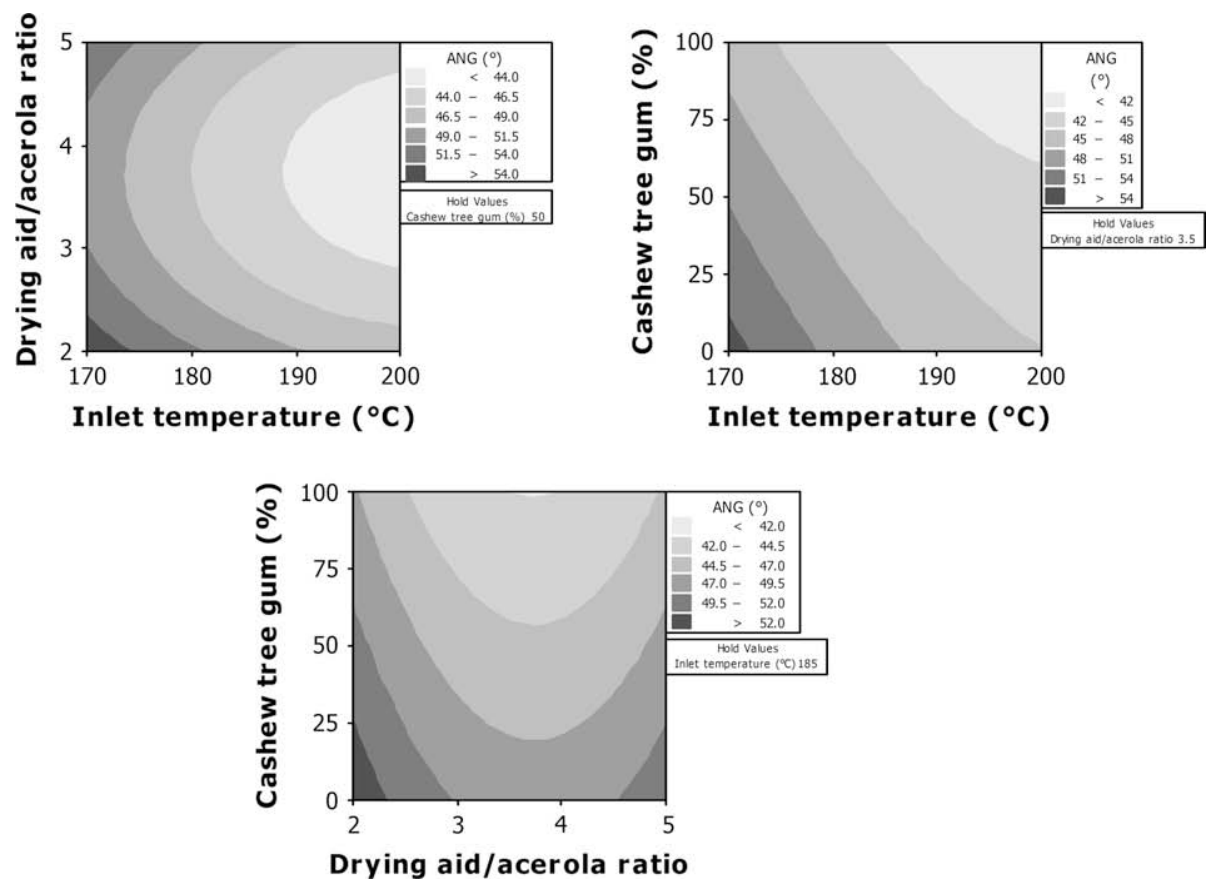

Fig. 2. Contour plots for angles of repose (in degrees) of the powders produced by spray drying acerola pomace extract.

not been found, the similarity between CTG and arabic gum structures suggest that both must have similar $T_{g}$ effects. So, this result may be compared to those by Righetto and Netto (2000) and Collares et al. (2004), who reported that the $T_{g}$-increasing effect of arabic gum is higher than that of MD.

Most powders presented a tendency to flowability problems, according to the criteria suggested by Bhandari et al. (1998), who defined free-flowing powders as those having angles of repose below $45^{\circ}$. However, adequately free-flowing powders were produced at higher temperatures $\left(>194^{\circ} \mathrm{C}\right)$, with drying aid/ acerola ratio around 3.5:1-4.0:1, with the drying aid consisting of at least $80 \%$ of CTG. The hygroscopicity must not be evaluated by their absolute values, since the powders were exposed to unreal abusive conditions. Anyway, the powders produced at higher temperatures, higher drying aid/acerola ratio and high degree of replacement of MD by CTG were the least hygroscopic. Since solubility was maintained above $90 \%$ in powders produced by all treatments, the negative effect of the drying aid/acerola ratio on this response was not considered to optimize the processing conditions.

So, under the ranges studied in this work, the best processing conditions to obtain a free-flowing and least hygroscopic acerola pomace extract powder by spray drying were the following: inlet
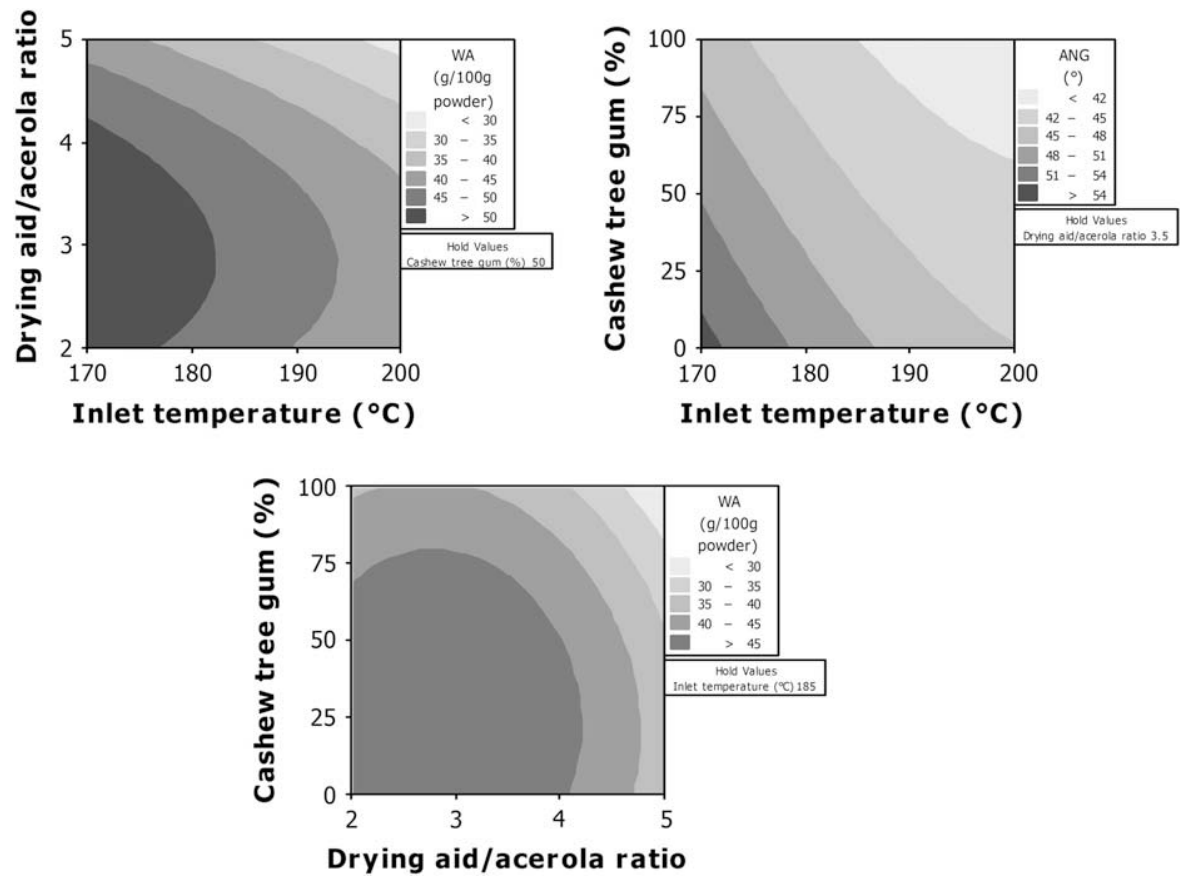

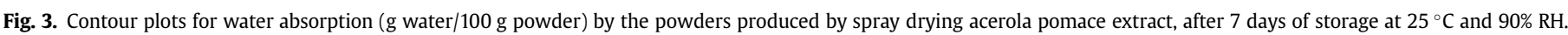



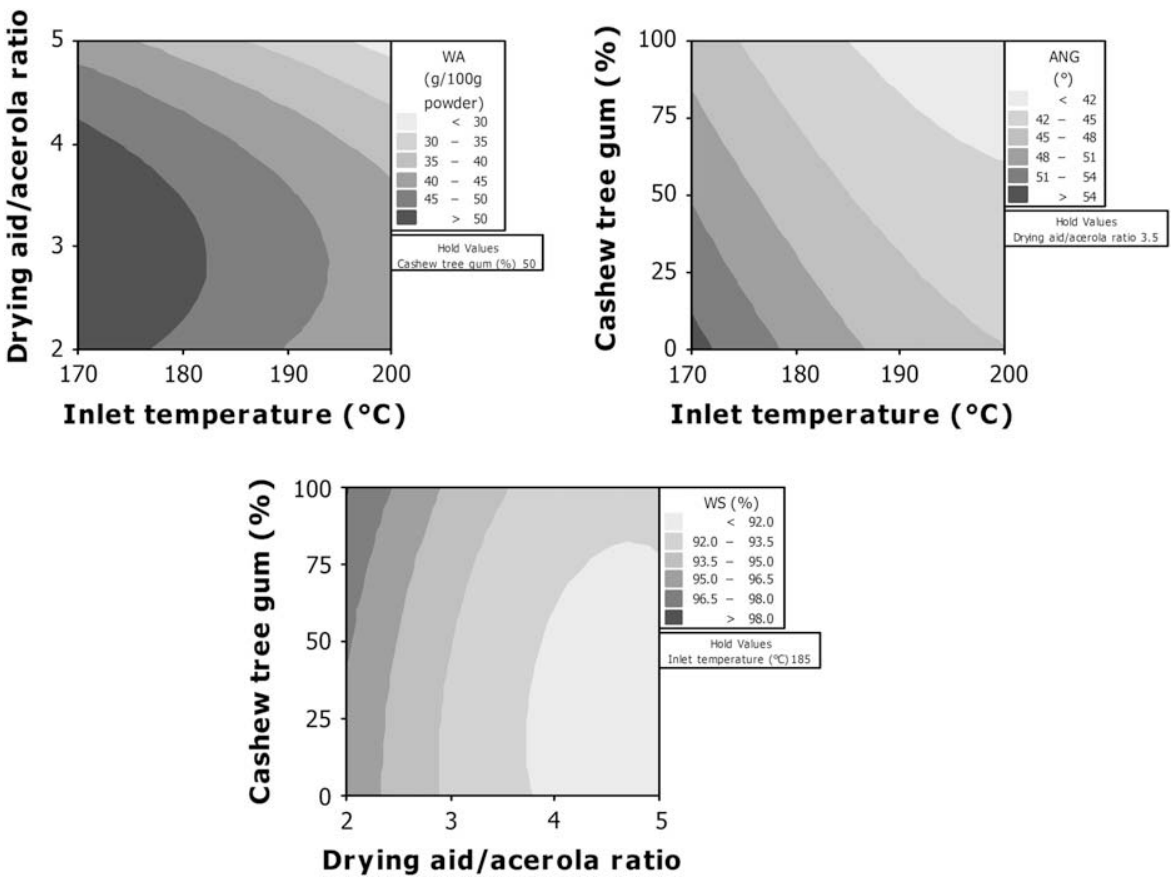

Fig. 4. Contour plots for water solubility ( $\mathrm{g}$ of powder per $100 \mathrm{~g}$ of water) of the powders produced by spray drying acerola pomace extract.

temperature above $194^{\circ} \mathrm{C}$; drying aid/acerola ratio of 4.0 , the drying aid being constituted by at least $80 \%$ cashew tree gum.

The cashew tree gum is abundant and inexpensive in several tropical developing countries. The assessment of new applications for this virtually unexploited polysaccharide may be important to motivate industries to recognize its potential. If properly exploited, cashew tree gum can greatly impact the cashew tree business and bring social-economical benefits to those countries.

\section{Acknowledgments}

The authors are grateful to $\mathrm{CNPq}$ (Conselho Nacional de Desenvolvimento Científico e Tecnológico, Brazil) for the financial support.

\section{References}

Abadio, F. D. B., Domingues, A. M., Borges, S. V., \& Oliveira, V. M. (2004). Physica properties of powdered pineapple (Ananas comosus) juice - effect of malt dextrin concentration and atomization speed. Journal of Food Engineering, 64(3) 285-287.

AOAC. (1995). Official methods of analysis of AOAC International (16th. ed.). Arlington, VA: AOAC.

Audu, T. O. K., Loncin, M., \& Weisser, H. (1978). Sorption isotherms of sugars. Lebensmittel-Wissenschaft und -Technologie, 11(1), 31-34.

Bhandari, B. R., Datta, N., D'Arcy, B. R., \& Rintoul, G. B. (1998). Co-crystallization of honey with sucrose. Lebensmittel-Wissenschaft und -Technologie, 31(2) 138-142.

Bhandari, B. R., Datta, N., \& Howes, T. (1997). Problems associated with spray drying of sugar-rich foods. Drying Technology, 15(2), 671-684.

Bhandari, B. R., \& Hartel, R. W. (2005). Phase transitions during food powder production and powder stability. In C. Onwulata (Ed.), Encapsulated and powdered foods (pp. 261-292). Boca Raton, FL: Taylor \& Francis.

Bhandari, B. R., Senoussi, A., Dumoulin, E. D., \& Lebert, A. (1993). Spray drying of concentrated fruit juices. Drying Technology, 11(5), 1081-1092.

Callahan, J. C., Cleary, G. W., Elefant, M., Kaplan, G., Kensler, T., \& Nash, R. A. (1982) Equilibrium moisture content of pharmaceutical excipients. Drug Development and Industrial Pharmacy, 8(3), 355-369.

Cano-Chauca, M., Stringheta, P. C., Ramos, A. M., \& Cal-Vidal, J. (2005). Effect of the carriers on the microstructure of mango powder spray drying and its functional characterization. Innovative Food Science \& Emerging Technologies, 6(4) 420-428.

Collares, F. P., Finzer, J. R., \& Kieckbusch, T. G. (2004). Glass transition control of the detachment of food pastes dried over glass plates. Journal of Food Engineering, 61(2), 261-267.
De Paula, R. C. M., Heatley, F., \& Budd, P. M. (1998). Characterisation of Anacardium occidentale exudate polysaccharide. Polymer International, 45, 27-35.

Dolinsky, A., Maletskaya, K., \& Snezhkin, Y. (2000). Fruit and vegetable powders production technology on the bases of spray and convective drying methods. Drying Technology, 18(3), 747-758.

Eastman, J. E. \& Moore, C. O. (1984). Cold water soluble granular starch for gelled food composition.

Fitzpatrick, J. J. (2005). Food powder flowability. In C. Onwulata (Ed.), Encapsulated and powdered foods (pp. 247-260). Boca Raton, FL: Taylor \& Francis.

Johnson, P. D. (2003). In A. P. Simopoulos, \& C. Gopalan (Eds.), Plants in human health and nutrition policy (pp. 67-75). Basel: Karger.

Leung, A. Y., \& Foster, S. (1996). Encyclopedia of common natural ingredients used in food, drugs, and cosmetics (2nd ed.). New York: Wiley. 6-7.

McNamee, B. F., O'Riordan, E. D., \& O'Sullivan, M. (1998). Emulsification and microencapsulation properties of gum arabic. Journal of Agricultural and Food Chemistry, 46, 4551-4555.

Mezadri, T., Fernández-Pachón, M. S., Villaño, D., García-Parrilla, M. C., \& Troncoso, A. M. (2006). El fruto de la acerola: composición. características productivas e importância econômica. Archivos Latinoamericanos de Nutrición, 56(2). http://www.alanrevista.org/ediciones/2006-2/fruto_acerola.asp. Available at Accessed 12.11.2006.

Owusu, J., Oldham, J. H., Oduro, I., Ellis, W. O., \& Barimah, J. (2005). Viscosity studies of cashew gum. Tropical Science, 45(2), 86-89.

Paula, H. C. B., Gomes, F. J. S., \& Paula, R. C. M. (2002). Swelling studies of chitosan/ cashew gum physical gels. Carbohydrate Polymers, 48(3), 313-318.

Peleg, M., \& Hollenbech, A. M. (1984). Flow conditioners and anti caking agents. Food Technology, 38(3), 93-102.

Righetto, A. M. \& Netto, F. M. (2000). Sorption isotherms of encapsulated unripe West Indian cherry (Malphigia glabra L) juice. In: ISOPOW 2000-8th International Symposium on the properties of water (p. 98). Zichron Yaakov.

Roos, Y. H. (2002). Importance of glass transition and water activity to spray drying and stability of dairy powders. Lait, 82, 475-484.

Roos, Y. H., \& Karel, M. (1992). Crystallization of amorphous lactose. Journal of Food Science, 57(3), 775-777.

Rosenthal, F. R. T. (1951). Goma do cajueiro: estudo químico e tecnológico. Rio de Janeiro: Instituto Nacional de Tecnologia.

Scoville, E., \& Peleg, M. (1981). Evaluation of the effect of liquid bridges on the bulk properties of model powders. Journal of Food Science, 46, 174-177.

Senoussi, A., Dumoulin, E. D., \& Berk, Z. (1995). Retention of diacetyl in milk during spray-drying and storage. Journal of Food Science, 60(5), 894-897.

Silva, M. A., Sobral, P. J. A., \& Kieckbusch, T. G. (2006). State diagrams of freeze-dried camu-camu (Myrciaria dubia (HBK) Mc Vaugh) pulp with and without maltodextrin addition. Journal of Food Engineering, 77(3), 426-432.

Torquato, D. S., Ferreira, M. L., Sá, G. C., Brito, E. S., Pinto, G. A. S., \& Azevedo, E. H. F. (2004). Evaluation of antimicrobial activity of cashew tree gum. World Journal of Microbiology \&' Biotechnology, 20, 505-507.

Yamashita, F., Benassi, M. T., Tonzar, A. C., Moriya, S., \& Fernandes, J. G. (2003). Produtos de acerola: estudo da estabilidade de vitamina C. Ciência e Tecnologia de Alimentos, 23(1), 92-94.

Zakaria, M. B., \& Rahman, Z. A. (1996). Rheological properties of cashew gum. Carbohydrate Polymers, 29(1), 25-27. 